Pathophysiology of Haemostasis and Thrombosis
Pathophysiol Haemost Thromb 2007-08;36:245-250

DOI: $\underline{10.1159 / 000252820}$
Received: June 5, 2009

Accepted after revision: September 17, 2009

\title{
Effects of Alteplase, a Thrombolytic Agent, in a Rat Photothrombotic Middle Cerebral Artery Occlusion Model
}

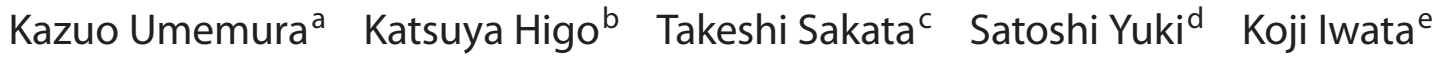 \\ Kazumasa Yamaguchi ${ }^{\mathrm{e}}$ \\ ${ }^{a}$ Department of Pharmacology, Hamamatsu University School of Medicine, Hamamatsu, ${ }^{b}$ Department of \\ Non-Clinical Development, Division of Development, Kyowa Hakko Kirin Co., Ltd., Shizuoka, 'Development Project \\ Management Department and dPharmacology Department I, Pharmacology Laboratory, Research Division, \\ Mitsubishi Tanabe Pharma Corporation, Osaka, and eNihon Bioresearch Center Inc., Gifu, Japan
}

\section{Key Words}

Photothrombotic occlusion - Thrombolytic agent •

Cerebral ischemia

\section{Abstract}

In this study, we examined the effects of alteplase, a recombinant tissue-type plasminogen activator (t-PA), in a simple and reproducible rat middle cerebral artery (MCA) occlusion model induced by photoillumination with $12 \mathrm{mg} / \mathrm{kg}$ of rose bengal. A clinically equivalent dose of alteplase $(3 \mathrm{mg} / \mathrm{kg})$, which was administered just after thrombotic occlusion of the MCA, significantly reopened the thrombotic MCA occlusion in 16 of 23 animals (69.6\%) when compared with vehicle-treated animals (8 of 22 animals, 36.4\%). In addition, alteplase significantly reduced cerebral damage and improved neurological deficits. Although it has been reported that t-PA possesses neurotoxicity, the present findings suggest that alteplase was effective in a rat acute stroke model due to reopening of thrombotic MCA occlusion. This new model is very useful for investigating the efficacy of thrombolytic agents in stroke research, providing a condition similar to the clinical setting.

Copyright ๑ 2009 S. Karger AG, Basel

\section{Introduction}

The potential for treating acute cerebral infarction with thrombolytic agents has generated much interest $[1,2]$. For the purpose of evaluating thrombolytic properties of thrombolytic agents in nonhuman studies, several animal models of acute stroke caused by middle cerebral artery (MCA) occlusion have been reported. These include MCA ligation [3], compression [4], coagulation, cutting [5] or embolization [6]. We established a simple and reproducible model of MCA occlusion in rats due to thrombosis, which was induced by a photochemical reaction between green light and intravenously injected rose bengal [7].

Previous works using this rat photothrombotic MCA occlusion model have been designed for detecting the antithrombotic or neuroprotective activities of the compounds [8-12] or for detecting the superiority of concomitant therapy over monotherapy with a thrombolytic agent $[13,14]$. The conditions of thrombus formation in those studies are somewhat severe, because for the purpose of detecting a neuroprotective effect, a hard, nonspontaneously opening thrombus is required. Therefore,

\section{KARGER}

Fax +4161306 1234

E-Mail karger@karger.ch

www.karger.com
(C) 2009 S. Karger AG, Basel

1424-8832/08/0365-0245\$24.50/0

Accessible online at:

www.karger.com/pht
Satoshi Yuki

1000, Kamoshida-cho, Aoba-ku

Yokohama, Kanagawa, 227-0033 (Japan)

Tel. +81 45963 3588, Fax +81459634209

E-Mail yuki.satoshi@mg.mt-pharma.co.jp 
Fig. 1. Schematic illustration of animal preparation (a) and experimental proto$\operatorname{col}(\mathbf{b})$. a
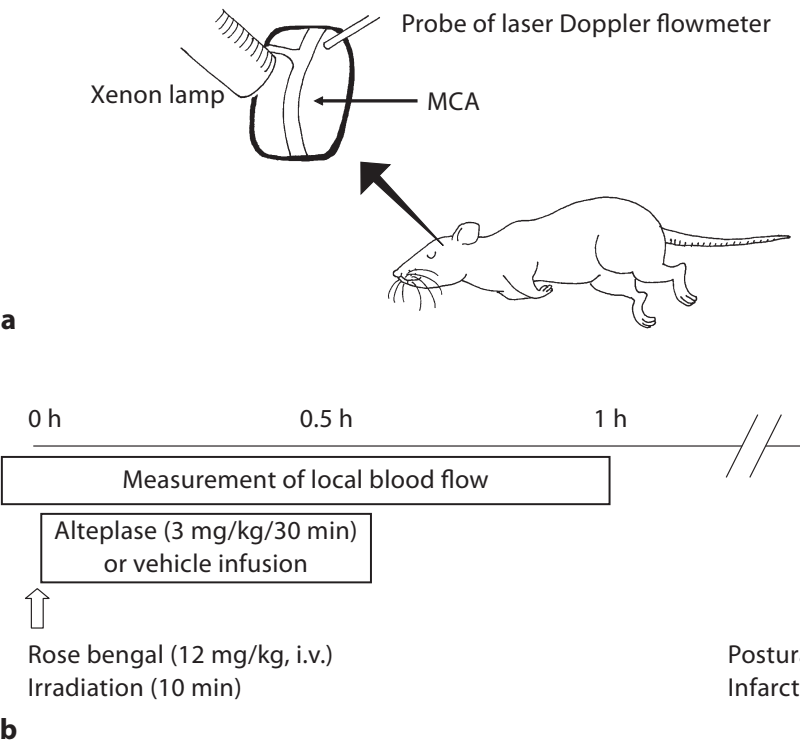

$24 \mathrm{~h}$

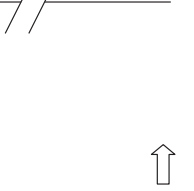

Postural reflex test Infarct size measurement we optimized the experimental condition prior to the present study and established the appropriate model for evaluating thrombolytic agents.

In the present study, using this improved model, we investigated the effects of alteplase, a recombinant tissuetype plasminogen activator ( $t-P A)$, on reopening rate, infarct size and neurological deficits.

\section{Methods}

\section{Animal Preparation}

The experimental protocol was approved by the Nihon Bioresearch Inc. Committee on Ethics of Animal Experimentation, and extra care was taken to avoid causing animal suffering. Male Sprague-Dawley rats (SLC, Japan), weighing 279-300 g, were anesthetized with halothane (3\% induction, $0.5-1.5 \%$ maintenance). The body temperature of the animals was maintained at $37.5 \pm 0.5^{\circ} \mathrm{C}$ with a heating pad (ATB-1100, Nihon Koden, Japan). The left MCA was then thrombotically occluded by the photochemical reaction [15]. Briefly, a catheter for drug or rose bengal administration was inserted into the femoral vein. The scalp and temporalis muscle were folded over, and a subtemporal craniotomy was performed using a dental drill under an operating microscope to open a $10-\mathrm{mm}$ diameter oval bony window. The window was irradiated with green light (wavelength $540 \mathrm{~nm}$ ) employing a xenon lamp (L4887, Hamamatsu Photonics, Japan) with a heatabsorbing filter and a green filter. The irradiation was directed by a 3-mm diameter optic fiber mounted on a micromanipulator. The head of the optic fiber was placed on the window in the skull base $2 \mathrm{~mm}$ above the artery. Photoillumination was performed for
$10 \mathrm{~min}$ after intravenous injection of rose bengal (12 mg/kg). Following the induction of MCA occlusion, the temporalis muscle and skin were closed in layers and anesthesia was discontinued.

Local blood flow in the MCA was measured continuously for $60 \mathrm{~min}$ after the photothrombotic occlusion employing a laser Doppler flowmeter (ALF 21, Advance, Japan), which was mounted on another manipulator, and data from the laser Doppler flowmeter were recorded on a Mac Lab data system (8S, AID Instruments Inc., Japan). The probe was placed on the MCA segment proximal to the irradiated area. After closure of the operation wounds, the animals were allowed to recover from the anesthesia.

Arterial blood gases $\left(\mathrm{pO}_{2}\right.$ and $\left.\mathrm{pCO}_{2}\right)$ were monitored before and 60 min after the photothrombotic occlusion using a Rap Top type blood analyzer (AVL OPTI Critical Care Analyzer, Sysmex Corporation, USA). The surgical site, the setup of the equipment, the timeline of measurement and the appropriate dose of rose bengal $(12 \mathrm{mg} / \mathrm{kg}, 1 \mathrm{ml} / \mathrm{kg})$ and alteplase $(3 \mathrm{mg} / \mathrm{kg}, 1 \mathrm{ml} / \mathrm{kg})$ are illustrated in figure 1.

Employing the method of Bederson et al. [16], neurological symptoms such as hemiplegia were evaluated in a posture test $24 \mathrm{~h}$ after photothrombosis. This evaluation was carried out in a blind fashion.

In postural reflex tests, hemiparesis of animals was observed. Rats were tested for their degree of abnormal posture when suspended by their tail $1 \mathrm{~m}$ above the floor. They were scored according to the following criteria: 0 , rats extend both forelimbs straight, no observable deficit; 1 , rats attach the right forelimb to the breast and extend the left forelimb straight; 2 , rats display decreased resistance to lateral push in addition to behavior as in score 1 without circling; 3 , rats twist the upper half of their body in addition to behavior as in score 2 . 
Fig. 2. Typical tracing of MCA local blood flow recorded with the laser Doppler flowmeter.

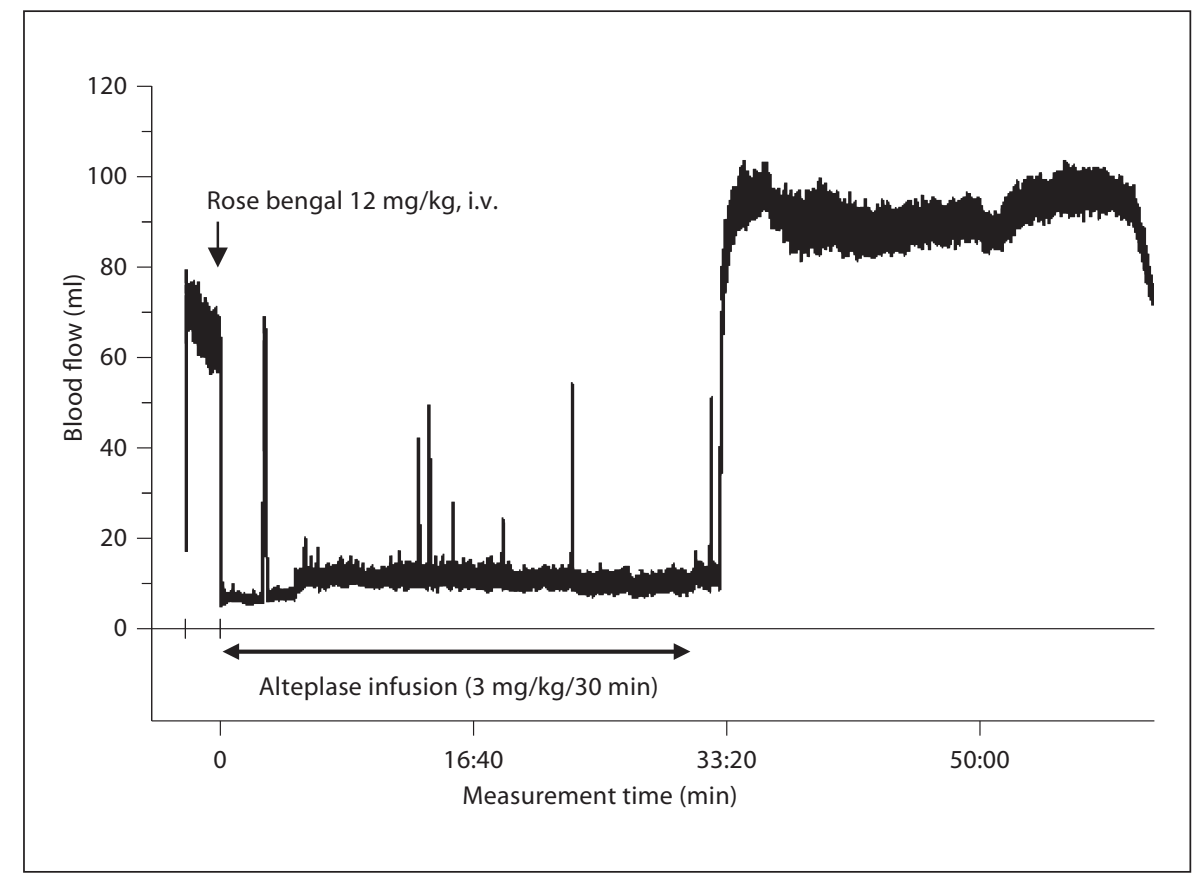

After measurement of neurological symptoms, the brain was quickly removed under ether anesthesia and then sectioned coronally into 2-mm-thick slices from the frontal lobe using a brain matrix (RBM4000V, Bioresearch Center, Japan). Seven consecutive slices were stained with $2 \%$ triphenyltetrazolium chloride (Nacalai Tesque Inc., Japan) and subsequently photographed. For each section, the infarct (white) and noninfarct (red) areas were determined by computerized image analysis on a Window XP computer using Win Roof (version 3.51, Mitani Corporation, Japan).

\section{Drug Administration}

Alteplase (Kyowa Hakko Kirin Co., Ltd., Japan) was administered at a dose of $3 \mathrm{mg} / \mathrm{kg}$ by a 30 -min continuous intravenous infusion using a microsyringe pump (type 100, USA) immediately after induction of photothrombotic occlusion. In the control group, saline was administered in the same manner.

\section{Determination of Plasma Concentration of $t-P A$}

In another set of experiments, the plasma concentration of t-PA was determined using different animals $(n=13)$. Arterial blood was taken from the femoral artery at 15 and 30 min after starting alteplase infusion $(3 \mathrm{mg} / \mathrm{kg}$ ). Plasma samples obtained from the blood were used for the assay. The plasma concentration of t-PA was determined by t-PA Antigen ELISA (Technoclone $\mathrm{GmbH}$, Austria).

\section{Data Analysis}

Data are presented as the means \pm SE. Cerebral infarct size was analyzed by the two-tailed unpaired Student $t$ test, and neurological deficits were analyzed by Wilcoxon's test. A p value $<0.05$ was considered significant.

Effects of Alteplase in a Rat Photothrombotic MCA Occlusion Model

\section{Results}

A total of 66 rats were used in the study. Of these, 21 were excluded from the data because of death during the experiment (2 rats), surgical failure (12 rats) or other reasons (7 rats). All physiological parameters (body temperature, $\mathrm{pH}, \mathrm{pO}_{2}$ and $\mathrm{pCO}_{2}$ of arterial blood) were within normal ranges after the MCA photothrombotic occlusion.

\section{Reopening Rate of Thrombotic MCA Occlusion}

A typical tracing of the MCA local blood flow is shown in figure 2. Alteplase reopened the MCA occlusion, and blood flow of the MCA then returned. Alteplase significantly $(\mathrm{p}<0.05)$ reopened the thrombotic MCA occlusion in 16 of 23 animals (69.6\%) when compared with the vehicle-treated animals (8 of 22 animals, 36.4\%). MCA blood flow values before thrombotic occlusion, after occlusion and $60 \mathrm{~min}$ after the termination of rose bengal injection (30 min after the termination of alteplase infusion) are shown in table 1.

\section{Effects of Alteplase on Neurological Deficits and Cerebral Infarct Size}

Animals in the control group exhibited impairment of posture reflex. Administration of alteplase significantly $(p<0.01)$ improved the neurological score (fig. 3). Fur- 
Table 1. Cerebral blood flow volume in thrombotic MCA occlusion

\begin{tabular}{|c|c|c|c|c|c|c|c|c|c|}
\hline $\begin{array}{l}\text { Control } \\
\text { group } \\
\text { No. }\end{array}$ & $\begin{array}{l}\text { before } \\
\text { infarct }\end{array}$ & $\begin{array}{l}\text { after } \\
\text { infarct }\end{array}$ & $\begin{array}{l}\text { after } \\
\text { admin. }\end{array}$ & $\begin{array}{l}\text { Reopen- } \\
\text { ing }\end{array}$ & $\begin{array}{l}\text { Alteplase } \\
\text { group } \\
\text { No. }\end{array}$ & $\begin{array}{l}\text { before } \\
\text { infarct }\end{array}$ & $\begin{array}{l}\text { after } \\
\text { infarct }\end{array}$ & $\begin{array}{l}\text { after } \\
\text { admin. }\end{array}$ & $\begin{array}{l}\text { Reopen- } \\
\text { ing }\end{array}$ \\
\hline 101 & 63.7 & 10.9 & 5.5 & & 201 & 85.2 & 14.8 & 27.3 & yes \\
\hline 102 & 44.5 & 9.4 & 10.2 & & 202 & 54.7 & 5.9 & 16.8 & \\
\hline 103 & 48.0 & 8.2 & 81.3 & yes & 203 & 50.8 & 8.6 & 11.7 & \\
\hline 106 & 35.2 & 7.8 & 12.1 & & 206 & 35.9 & 9.4 & 93.0 & yes \\
\hline 107 & 55.1 & 8.6 & 85.9 & yes & 207 & 65.2 & 13.7 & 32.8 & yes \\
\hline 108 & 50.8 & 19.9 & 21.1 & & 208 & 40.6 & 10.5 & 57.8 & yes \\
\hline 109 & 37.1 & 4.7 & 5.9 & & 209 & 55.5 & 4.3 & 65.6 & yes \\
\hline 110 & 44.9 & 19.9 & 20.3 & & 210 & 49.2 & 7.0 & 56.6 & yes \\
\hline 115 & 51.6 & 6.3 & 6.3 & & 215 & 59.8 & 17.2 & 63.7 & yes \\
\hline 116 & 33.2 & 11.7 & 55.9 & yes & 216 & 86.3 & 17.2 & 22.7 & yes \\
\hline 117 & 56.3 & 21.1 & 18.8 & & 217 & 48.8 & 9.8 & 96.1 & yes \\
\hline 118 & 39.5 & 3.5 & 12.9 & & 218 & 40.6 & 17.2 & 23.4 & \\
\hline 119 & 45.7 & 22.3 & 33.2 & yes & 219 & 46.9 & 6.3 & 87.9 & yes \\
\hline 120 & 47.7 & 9.4 & 62.9 & yes & 220 & 50.4 & 8.6 & 78.1 & yes \\
\hline 121 & 46.1 & 21.1 & 28.9 & yes & 221 & 50.0 & 17.6 & 25.8 & \\
\hline \multirow[t]{2}{*}{122} & 52.0 & 72.7 & 7.0 & & 222 & 55.1 & 7.4 & 9.4 & \\
\hline & & & & & 223 & 43.4 & 9.4 & 42.6 & yes \\
\hline
\end{tabular}

The control group was given $1 \mathrm{ml} / \mathrm{kg}$ vehicle (saline) by 30 -min intravenous infusion. The alteplase group was given $3 \mathrm{mg} / \mathrm{kg}$ alteplase $(1 \mathrm{ml} / \mathrm{kg})$ by 30 -min intravenous infusion. After admin. $=$ After administration, i.e. 30 min after the termination of alteplase infusion.

ther, administration of alteplase significantly $(\mathrm{p}<0.01)$ reduced the cerebral infarct size $24 \mathrm{~h}$ after MCA occlusion (fig. 4).

\section{Plasma Concentration of $t-P A$}

The plasma concentrations of t-PA at $3 \mathrm{mg} / \mathrm{kg}$ of alteplase were $2.47 \pm 0.31 \mu \mathrm{g} / \mathrm{ml} 15 \mathrm{~min}$ after starting the infusion and $2.24 \pm 0.43 \mu \mathrm{g} / \mathrm{ml}$ after $30 \mathrm{~min}$.

\section{Discussion}

In the present paper, we describe a simple and reproducible model for evaluating the effects of thrombolytic agents on cerebral infarction induced by thrombotic MCA occlusion. There are many kinds of MCA occlusion rat models such as thromboembolic occlusion [6] or ligation and reperfusion $[3,5,17]$. However, these models are not exactly mimicking the clinical situation of cerebral ischemia. The photothrombotic occlusion model results in a platelet- and fibrin-rich thrombus in the MCA at the irradiated site $[7,8]$, which resembles arteriosclerotic thrombus-mediated stroke. On the other hand, clots, used in an embolic model, are composed of only fibrin, not platelets. Furthermore, in previous reports in which photothrombotic thrombus models are used, there are few papers in which the authors evaluate the simple (clot dissolving) effect of thrombolytic agents like t-PA. Almost all the reports are designed for evaluating the antithrombotic or neuroprotective activities of the compounds [8-12] or for demonstrating the advantage of concomitant therapy over monotherapy using t-PA $[13,14]$. In the former cases, the condition of thrombus formation was too severe to meet the situation that a spontaneous reopening should not be established. In the preliminary study, we have tried to optimize the condition of thrombus formation for eval- 


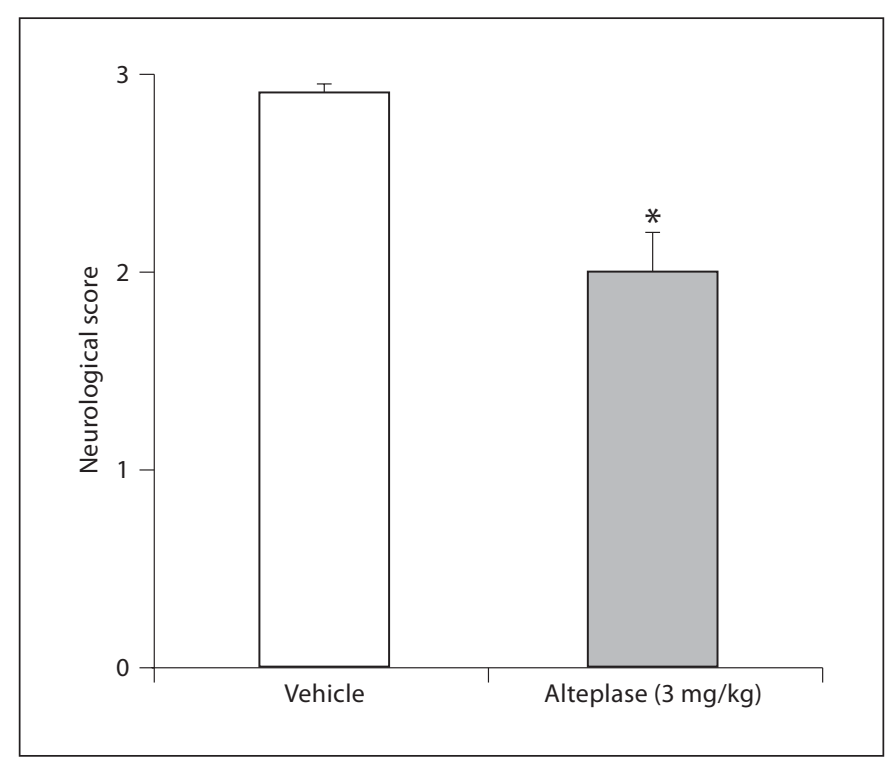

Fig. 3. Effect of alteplase on neurological deficits. Each column represents the mean \pm SE. ${ }^{*} \mathrm{p}<0.01$ versus control.

uation of thrombolytic agents. We determined an appropriate dose of rose bengal, which is critical for defining the severity of the thrombus. The thrombus formed after 20 $\mathrm{mg} / \mathrm{kg}$ of rose bengal administration was too severe and the dose of t-PA which is close to the clinically effective concentration could not dissolve the thrombus significantly. The thrombus formed after $8 \mathrm{mg} / \mathrm{kg}$ of rose bengal administration was too loose and more than half of the animals examined did not show thrombus formation. We determined that $12 \mathrm{mg} / \mathrm{kg}$ of rose bengal is best for evaluating thrombolytic agents singly administered shortly after the thrombus formation.

We used $3 \mathrm{mg} / \mathrm{kg}$ of alteplase in this experiment. Taking into account the rapid clearance of alteplase in rats and species difference in efficacy between rats and humans (alteplase has an amino acid array of human t-PA), we considered that a 3 - to 5 -fold dosage was required in comparison with the clinical dosage so as to show a similar efficacy and plasma concentration in rats compared with humans. In our study, the plasma concentration of t-PA following a 30-min infusion of $3 \mathrm{mg} / \mathrm{kg}$ alteplase was almost the same as that used in the clinical setting for patients with acute myocardial infarction, in whom $100 \mathrm{mg}$ of alteplase was administered for a mean body weight of about $80 \mathrm{~kg}$ [18].

Further advantages of this model over other cerebral ischemia models are as follows. (1) Clots, which can be dis-

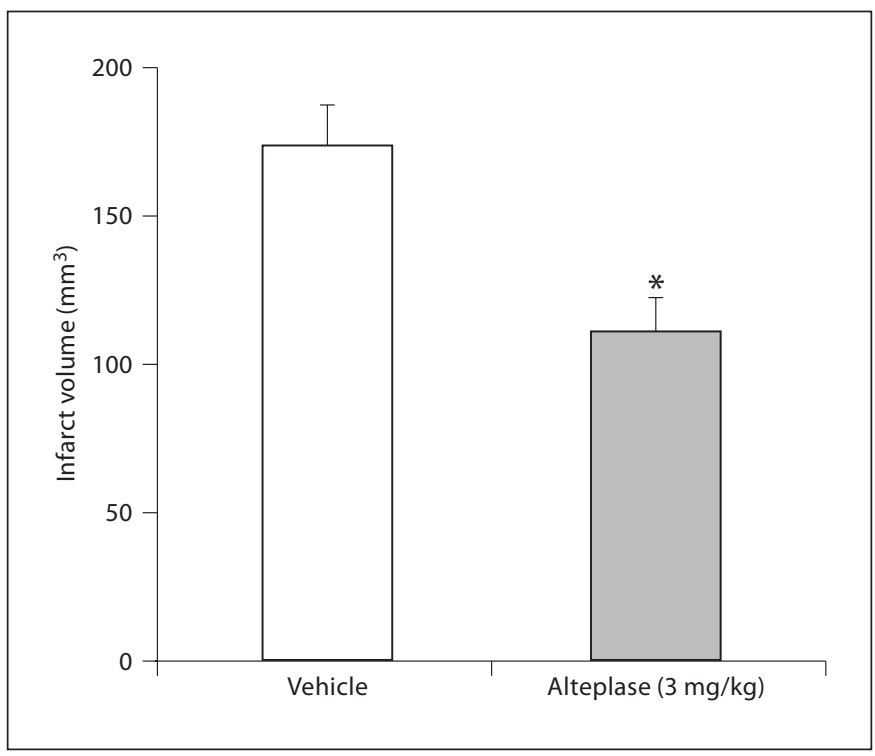

Fig. 4. Effect of alteplase on cerebral infarct size. Each column represents the mean $\pm \mathrm{SE} .{ }^{*} \mathrm{p}<0.01$ versus control.

solved by the thrombolytics, are made reproducibly at the same MCA position, and blood flow or reopening can be observed with laser Doppler flowmetry. (2) The dura mater remains intact, and surgical invasiveness is less severe than that of the electrical coagulation model. (3) The xenon lamp has a heat-absorbing filter, and therefore elevation of the temperature at the site of irradiation is avoided.

We have not determined the impact of the rat strain difference on the extent of cerebral ischemia and on the effect of thrombolytic properties of t-PA in the present study. Sprague-Dawley rats are reported to be susceptible to focal ischemia induced by reduced blood flow compared with Wistar rats [19], but in the present study, we did not directly compare these two strains of rats. In what way the strain difference influences the condition of the model remains to be elucidated.

In patients with acute stroke, intravenous thrombolytic therapy within $3 \mathrm{~h}$ of onset is beneficial. However, recent reports have indicated that t-PA has a toxicity towards neurons [20]. The efficacy of t-PA in acute stroke may thus depend on a balance between thrombolytic effects and neurotoxicity.

In conclusion, on this basis, we suggest that the present MCA occlusion model of thrombotic ischemia is very useful for investigating the efficacies of thrombolytic agents in stroke research, as a condition similar to the clinical setting. 


\section{References}

$>1$ The ATLANTIS, ECASS, and NINDS rt-PA Study Group Investigators: Association of outcome with early stroke treatment: pooled analysis of ATLANTIS, ECASS, and NINDS rt-PA stroke trials. Lancet 2004;363:768774.

-2 The NINDS rt-PA Stroke Study Group: Tissue plasminogen activator for acute ischemic stroke. N Engl J Med 1995;333:1581-1587.

-3 Tamura A, Graham DI, McCulloch J, Teasdale GM: Focal cerebral ischemia in the rat. 1. Description of technique and early neuropathological consequences following middle cerebral artery occlusion. J Cereb Blood Flow Metab 1981;1:53-60.

$\checkmark 4$ del Zoppo GJ, Copeland BR, Harker LA, Waltz TA, Zyroff J, Hanson SR, Battenberg E: Experimental acute thrombotic stroke in baboons. Stroke 1986;17:1254-1265.

$>5$ Brint S, Jacewicz M, Kiessling M, Tanabe J, Pulsinelli W: Focal brain ischemia in the rat: methods for reproducible neocortical infarction using tandem occlusion of the distal middle cerebral and ipsilateral common carotid arteries. J Cereb Blood Flow Metab 1988;8:474-478.

6 Ovagaard K, Sereghy T, Boysen G, Pedersen $\mathrm{H}$, Diemer NH: Reduction of infarct volume by thrombolysis with rt-PA in an embolic rat stroke model. Scand J Clin Invest 1993;53: 383-393.
7 Matsuno H, Uematsu T, Umemura K, Takiguchi Y, Asai Y, Muranaka Y, Nakashima M: A simple and reproducible cerebral thrombosis model in rats induced by photochemical reaction and the effect of a plasminogen-plasminogen activator chimera in this model. J Pharmacol Toxicol Methods 1993; 29:165-173.

$>8$ Mizuno A, Umemura K, Nakashima M: Inhibitory effect of MCI-186, a free radical scavenger, on cerebral ischemia following rat middle cerebral artery occlusion. Gen Pharmacol 1998;30:575-578.

$>9$ Kawai H, Yuki S, Sugimoto J, Tamao Y: Effects of a thrombin inhibitor, argatroban, on ischemic brain damage in the rat distal middle cerebral artery occlusion model. J Pharmacol Exp Ther 1996;278:780-785.

10 Umemura K, Gemba T, Mizuno A, Nakashima M: Inhibitory effect of MS-153 on elevated brain glutamate level induced by rat middle cerebral artery occlusion. Stroke 1996;27: 1624-1628.

11 Umemura K, Wada K, Uematsu T, Mizuno A, Nakashima M: Effect of 21-aminosteroid lipid peroxidation inhibitor, U74006F, in the rat middle cerebral artery occlusion model. Eur J Pharmacol 1994;251:69-74.

12 Umemura K, Shimakura A, Nakashima M: Neuroprotective effect of a novel AMPA receptor antagonist, YM90K, in rat focal cerebral ischaemia. Brain Res 1997;773:61-65.

-13 Umemura K, Toshima Y, Asai F, Nakashima M: Effect of dietary docosahexaenoic acid in the rat middle cerebral artery thrombosis model. Thromb Res 1995;78:379-387.

-14 Maeda M, Furuichi Y, Ueyama N, Moriguchi A, Satoh N, Matsuoka N, Goto T, Yanagihara $\mathrm{T}$ : A combined treatment with tacrolimus (FK506) and recombinant tissue plasminogen activator for thrombotic focal cerebral ischemia in rats: increased neuroprotective efficacy and extended therapeutic time window. J Cereb Blood Flow Metab 2002;22: 1205-1211.
15 Saniabadi AR, Umemura K, Matsumoto N, Sakuma S, Nakashima M: Vessel wall injury and arterial thrombosis induced by a photochemical reaction. Thromb Haemost 1995; 73:868-872.

16 Bederson JB, Pitts LH, Tsuji M, Nishimura MC, Davis RL, Bartkowski H: Rat middle cerebral artery occlusion: evaluation of the model and development of a neurologic examination. Stroke 1986;17:472-476.

17 Longa EZ, Weinstein PR, Carlson S, Cummins R: Reversible middle cerebral artery occlusion without craniectomy in rats. Stroke 1989;20:84-91.

18 Seifried E, Tanswell P, Ellbruck D, Haerer W, Schmidt A: Pharmacokinetics and haemostatic status during consecutive infusions of recombinant tissue-type plasminogen activator in patients with acute myocardial infarction. Thromb Haemost 1989;61:497501.

19 Bardutzky J, Shen Q, Henninger N, Bouley J, Duong TQ, Fisher M: Differences in ischemic lesion evolution in different rat strains using diffusion and perfusion imaging. Stroke 2005;36:2000-2005.

20 Nicole O, Docagne F, Ali C, Margaill I, Carmeliet P, MacKenzie ET, Vivien D, Buisson A: The proteolytic activity of tissue-plasminogen activator enhances NMDA receptor-mediated signaling. Nat Med 2001;7:5964. 